\title{
Comparison of Effectiveness of Facet Joint Injection and Radiofrequency Denervation in Chronic Low Back Pain
}

\author{
Kronik Bel Ağrisinda Faset Eklem Enjeksiyonu ve Radyofrekans \\ Denervasyonunun Etkilerinin Karşılaştırılması
}

\author{
Erdinc CIVELEK ${ }^{1}$, Tufan CANSEVER ${ }^{1}$, Serdar KABATAS ${ }^{1}$, Atilla KIRCELLI ${ }^{2}$, Cem YILMAZ $^{3}$, \\ Murat MUSLUMAN ${ }^{4}$, Demet OFLUOGLU ${ }^{5}$, Hakan CANER ${ }^{3}$ \\ ${ }^{1}$ Baskent University, Faculty of Medicine, Department of Neurosurgery, Istanbul, Turkey \\ ${ }^{2}$ Goztepe Safak Hospital, Department of Neurosurgery, Istanbul, Turkey \\ ${ }^{3}$ Baskent University, Faculty of Medicine, Department of Neurosurgery, Ankara, Turkey \\ ${ }^{4}$ Sisli Etfal Government Hospital, Department of Neurosurgery, Istanbul, Turkey \\ ${ }^{5}$ Baskent University, Faculty of Medicine, Department of Physical Therapy and Rehabilitation, Istanbul, Turkey
}

Correspondence address: Tufan CANSEVER / E-mail: drtufan@gmail.com

\begin{abstract}
AIM: The study was conducted to compare the clinical effectiveness of FJ injections (FJI) and FJ radiofrequency (FJRF) denervation in patients with chronic low back pain.

MATERIAL and METHODS: This study included 100 patients; 50 in FJ 50 in FJRF group. VNS, NASS and EQ-5D were used to evaluate the outcomes. All outcome assessments were performed at baseline, 3 months, 6 months and 12 months.

RESULTS: FJ in early post-op but FJRF in 1 st, 6 th and 12 th month VNS showed better results $(p<0.001)$. There was no significant difference in the 1st $(p=1)$ and 6th month $(p=0.13)$ but in 12th month $(p=0.04)$ in NASS. Increase in level number showed positive effect in NASS in FJRF group $(p=0.018)$ but no effect in FJ group $(p=0.823)$ in the 12th month follow-up. There was no significant difference with respect to 1 st month $(p=0.17)$, 6th month $(p=0.22)$ and 12th month $(p=0.11)$ post-procedure follow-ups in EQ-5D. At the short term FJI was more effective than FJRF however in midterm follow-up FJRF had more satisfying results than FJRF.
\end{abstract}

CONCLUSION: To our knowledge, the first choice should be the FJ and if pain reoccurs after a period of time or injection is not effective, RF procedure should be used for the treatment of chronic lumbar pain.

KEYWORDS: Facet, Joint, Injection, Radiofrequency, Denervation, Low back pain

öz

AMAÇ: Lomber faset eklem (FE) bozuklukları kronik bel ağrılarının en sık sebebidir. Bu çalışmada, kronik bel ağrılı hastalarda uygulanan FE enjeksiyonu (FEE) ve radyofrekans denervasyonunun (FER) klinik sonuçlarının karşılaştırılması amaçlamaktadır.

YÖNTEM ve GEREÇLER: Bu çalışmaya 50 FEE ve 50 FER yapılan 100 hasta dahil edildi. VNS, NASS ve EQ-5D sonuçların değerlendirilmesi amacıyla kullanıldı. Sonuçlar başlangıç, 3. ay, 6. ay ve 12. aylarda elde edildi.

BULGULAR: FEE işlem sonrası erken dönemde, FER ise 1., 6. ve 12. ayda daha etkiliydi $(p<0,001)$. NASS sonuçlarında 1 . $(p=1)$ ve 6. ayda $(p=0.13)$ anlamlı fark yokken 12 . ayda $(p=0,04)$ vardı. İşlem yapılan segment sayısı FER grubunun $(p=0,018) 12$. aydaki NASS sonucunu pozitif yönde etkilerken FEE grubunda ( $p=0,823)$ etkisi yoktu. EQ-5D sonuçları açısından 1. $(p=0,17), 6 .(p=0,22)$ ve 12. ayda ( $p=0,11)$ iki grup arasında anlamlı fark saptanmadı. Kısa dönemde FEE daha etkiliyken orta dönemde FER'in sonuçları daha başarılıydı.

SONUÇ: Faset eklemden kaynaklanan bel ağrılarında, FEE ve FER birer tedavi seçenekleridir. Sonuçlarımıza göre, kronik bel ağrısının tedavisinde FEE ilk seçenek olarak düşünülmeli ve bir süre sonra tekrarlayan veya FEE etkili olmadığı durumlarda FER tedavi amacıyla kullanılmalıdır.

ANAHTAR SÖZCÜKLER: Faset, Eklem, Enjeksiyon, Radyofrekans, Denervasyon, Bel ağrıları 


\section{INTRODUCTION}

The incidence of low back pain has been estimated at $5 \%$ and the lifetime prevalence ranges from $60 \%$ to $90 \%$ (11). However, chronic pain symptoms develop in only $10 \%$ to $20 \%$ of these patients. Some studies have shown that chronicity or recurrence of low back pain is seen in $35 \%$ to $79 \%$ of patients $(7,34)$. Among the causes of low back pain, lumbar FJ (FJ) syndrome is reported to have a prevalence of $15 \%$ to $52 \%$ $(2,21)$. The patients typically have relatively longstanding and not acute onset pain. There may be unilateral or bilateral pain and there is often limitation of movement with pain on flexion, extension, or rotation. Direct palpation to the involved facet may be painful on physical examination. On examination, direct off-lateral pressure to the spinous process may simulate pain from the abnormal FJ. FJs are innervated by the medial branches of the dorsal rami and FJ pain may be managed by intraarticular injections, FJ nerve blocks, and neurolysis of $\mathrm{FJ}$ nerves.

Bogduk et al. (1) suggested that intraarticular FJls were no better than placebo for chronic lumbar spine pain. Boswell et al. $(3,4)$ showed moderate evidence for lumbar intraarticular FJls for short-term improvement, but only limited evidence for long-term improvement. For medial branch blocks with injection, the evidence was moderate for short- and longterm pain relief. For RF, the evidence was moderate for shortand long-term pain relief $(3,4)$. Geurts et al. (13) concluded that there was moderate evidence that radiofrequency lumbar facet denervation was more effective for chronic low back pain than placebo.

Although there are many studies related to effectiveness of facet interventions for chronic lumbar pain, there is a limited number of studies comparing the effectiveness of FJIs and RF. Our aim is to report the comparison of the effectiveness of FJls and FJRF denervation in 100 patients with chronic low back pain.

\section{MATERIAL and METHODS}

In this study, we evaluated the patients with chronic low back pain not responsive to traditional conservative treatment, such as trial of bed rest, medication and physical therapy. Randomization into two groups was performed by random number generation, balancing after every ten patients.

Inclusion criteria were chronic and debilitating LBP leading to a diagnosis of a lumbar facet syndrome, not responding to conservative treatment for up to 6 weeks including various analgesics and physical therapy and additionally pain relief after FJI for FJRF patients. The symptoms of facet syndrome are local tenderness over one or more FJs, back pain aggravation by hyperextension and rotation, morning stiffness or pain increasing in the morning and hip and buttock pain of a nonradicular distribution.

In our patient population, radiographic findings were evaluated as follows: lumbosacral $x$-rays were examined for narrowing of FJ, osteoarthritis with narrowing, facet hypertrophy, eburnation, and osteophyte formation. Regarding lumbosacral computed tomography findings, facet arthrosis, related central spinal canal, lateral recess, neural foramen stenosis, and posterior element alterations associated with various forms of spondylolisthesis were evaluated as well. Related to lumbosacral magnetic resonance imaging, degenerative changes of the FJs including erosion of the articular cartilage associated with joint space narrowing, periarticular hyperostosis with osteophyte formation, subchondral bone changes (eg, eburnation), and soft tissue changes (eg, thickening/calcification of the ligamentum flavum and FJ synovial cyst formation) were detected in presurgical assessments.

Exclusion criteria were patients having radicular pain, neurogenic claudication, and neurological deficits. The patients having an acute or uncontrolled medical illness, known history of adverse reactions to local anesthetics and pregnant or lactating women were also excluded from the study.

FJl was performed to 50 patients with a mean age of $56.5 \pm 17.7$ years and $70.8 \%$ of them were female. The procedure was performed to $22(54 \%)$ patients from one level, $13(26 \%)$ from 2 levels, 8 (16\%) from 3 levels and 2 (4\%) from 4 levels. The patients had been suffering from their symptoms for $18.7 \pm 12.3$ months. FJRF was performed to 50 patients with a mean age of $51.8 \pm 17$ years and $70 \%$ of them were female. The procedure was performed to $21(52 \%)$ patients from one level, 14 (28\%) from 2 levels, 9 (16\%) from 3 levels and $2(4 \%)$ from 4 levels. The patients had been suffering from their symptoms for $18.9 \pm 12.9$ months. Institutional review board approval and written informed consent were obtained for this study. The advantages and disadvantages of the both procedures were carefully explained to the patients and their families.

Both of the procedures were performed in an operating room equipped with fluoroscopy while the patient lay prone. Sedation was not used to provide adequate feedback during the procedures and to prevent some complications as a result of improper needle positioning. We did not use skin anesthesia to decrease the rate of false positiveness in our series.

After randomization, 50 patients in the first treatment group were subjected to a FJ with a medial branch block of the posterior primary ramus with $1 \mathrm{cc}$ of methyl-prednisolone acetate $(40 \mathrm{mg}$ ) (diluted with $1 \mathrm{cc}$ SF) combined with 2 cc bupivacaine hydrochloride (diluted with 2 cc SF). The second group of 50 patients was treated with radiofrequency denervation at $80 \mathrm{C}$ temperature for 120 seconds.

Improper anatomic locations leading to an ineffective radiofrequency articular facet denervation and ineffective medial branch block via injection are always a possibility. In this study, two experienced specialists who had performed the techniques for more than 5 years were employed.

In the FJ procedure, a standard $10-\mathrm{cm} 21-\mathrm{g}$ spinal needle was used. Syringes were needed for local anesthetic $(8 \mathrm{~mL}$ 
lidocaine, $1 \%$ mixed with $2-3 \mathrm{~mL}$ bicarbonate), contrast material (3 mL nonionic contrast, such as iohexol $240 \mathrm{mgl} /$ $\mathrm{mL}$ ), and the steroid/anesthetic mixture. We used $40 \mathrm{mg}$ methyl-prednisolone acetate ( $1 \mathrm{~mL}$ volume) mixed with 1.5-2 $\mathrm{mL}$ bupivacaine $(0.25 \%-0.5 \%)$. The patient was placed prone; the back was thoroughly cleansed and sterile drapes were applied. The fluoroscopy was then placed at slightly oblique view and the trajectory to the FJ was chosen Figure $1 \mathrm{~A}, \mathrm{~B}$. After application of local anesthetic (lidocaine, $1 \%$ mixed with bicarbonate), the needle was inserted and advanced to the FJ. The medial branch of the dorsal spinal ramus was the main target.

In the RF procedure, electrode location was confirmed first by sensory stimulation at $50 \mathrm{~Hz}$ and motor stimulation at $2 \mathrm{~Hz}$, to a maximum of $1 \mathrm{~V}$ each. No local anesthesia was used to confirm the adequate position with the stimulation. The medial branch of the dorsal spinal ramus is the main target. The nerve courses around the neck of the superior articular process of the FJ. It courses caudal and slightly dorsal between the junction of the superior articular process of the facet and the transverse process (Figure 1A, B). The fluoroscopy was then placed at slightly oblique view (Figure $1 \mathrm{~A}, \mathrm{~B})$. An 18-gauge insulated RF needle with $5 \mathrm{~mm}$ active tip was used by entering slightly superior and lateral to the target where the medial branch crosses between the junction of the superior facet process and transverse process. Resistance was checked once the electrode was in place and was generally between 200 and $500 \Omega$. Sensory testing was performed at $50 \mathrm{~Hz}$ at $1 \mathrm{~V}$ with 1-millisecond pulse duration. The aim was to produce pain, pressure, or tingling and without distal extremity stimulation. Motor testing was then performed at $2 \mathrm{~Hz}$ at $3 \mathrm{~V}$ with 1 -millisecond pulse duration. The patient was carefully observed for any extremity muscle contraction. Then, a 5-mm active tip electrode was used to create a single lesion at $80^{\circ} \mathrm{C}$ for 120 seconds. We did not perform post RF injection of steroids or local anesthetics to decrease the rate of false positiveness.
Patients were generally observed for 24 hours post procedure and then discharged. They were instructed to rest the treated region for several days and avoid activities that would typically produce pain. A prescription for 1 week of pain control was provided.

The interviews were conducted by telephone by using the Visual Numeric Pain Scale (VNS), North American Spine Society (NASS) patient satisfaction questionnaire and (EuroQol in 5 dimensions) EQ-5D. VNS measured experienced pain with 0 representing no pain and 10 representing the worst pain imaginable. The treatment outcome was evaluated by direct questioning by a nurse who did not know the patient history and the procedure performed.

\section{Follow-up and clinical evaluation}

VNS, NASS and EQ-5D were used to evaluate the therapeutic efficacy (12). VNS measured experienced pain with 0 representing no pain and 10 representing the worst pain imaginable. The EQ-5D descriptive system comprises the following 5 dimensions: mobility, self-care, usual activities, pain/discomfort and anxiety/depression. Each dimension has 3 levels: no problems, some problems, extreme problems. A score of 5 was representing best score and 15 the worst score. In the NASS classification 1 represents fully meeting of patient's expectation, 2 less improvement than the hoped for result but the patient would undergo the same procedure again, 3 the procedure helped but the patient would not undergo again and 4 the same or worse status with respect to pre-operative status. Patients were evaluated before the procedure and at one week after the procedure. Those who responded favorably to the procedure were then placed in a spine rehabilitation program for four to six weeks to maximize the functional gains. Those who did not respond or responded partially were offered either surgery or physical therapy. VNS and EQ-5D was recorded at the first clinical examination prior to procedures. Patients were asked prior to, soon after,

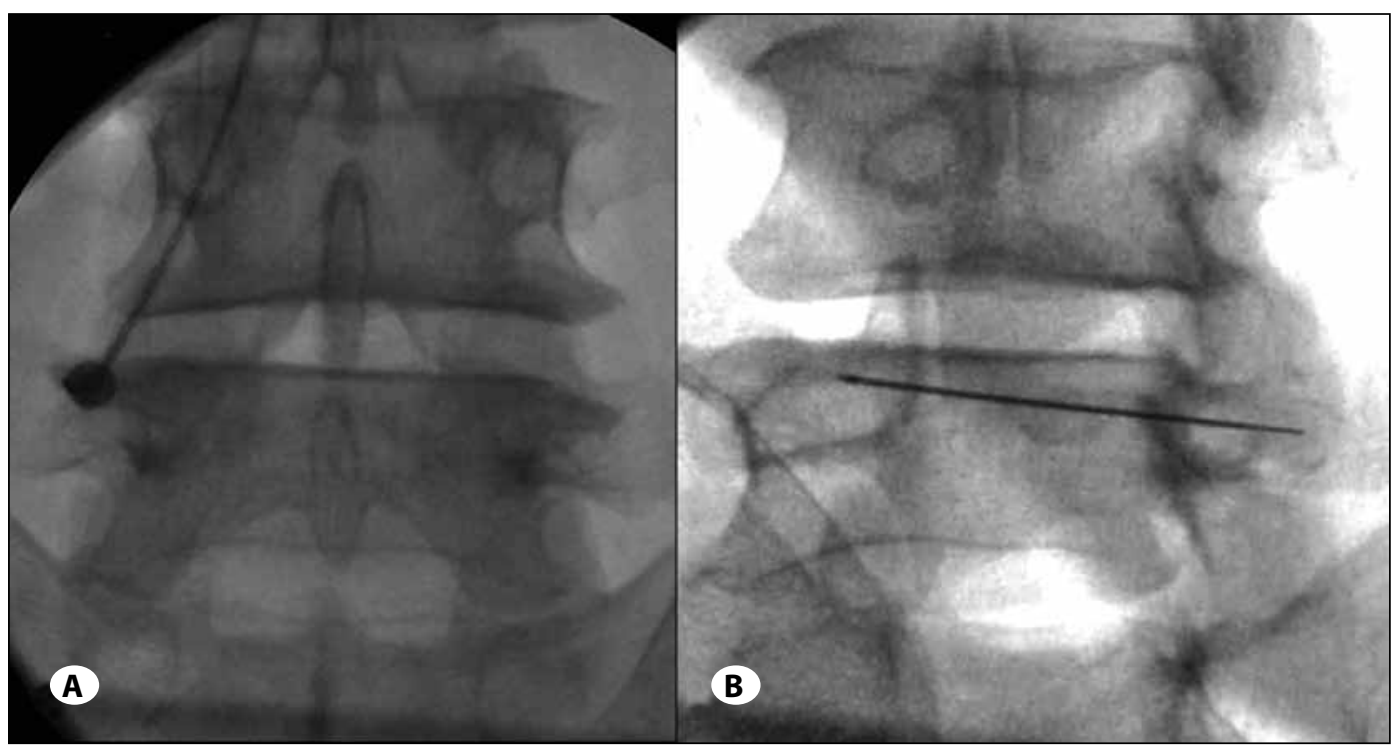

Figure 1: Fluoroscopic visualization of the superior articular facet and transverse process (A). The electrode was advanced until bone contact in anteroposterior projection. Oblique (B) projection was taken to confirm tip positioning which shows that the electrode tip remains in the base of the superior articular process (B). 
and one week after the procedure. Patient outcomes were assessed one month after the procedure (short term) by a physical therapy and rehabilitation specialist (D. M.) who was blinded to the pre-procedure scores. The evaluator used VNS, EQ-5D and NASS to assess the patient's own assessment with regard to the degree of improvement. Patients were then reevaluated over the phone by a blinded independent observer (A. K.) at $6^{\text {th }}$ month, $1^{\text {st }}$ year and $2^{\text {nd }}$ year. A reduction in the VNS of more than $50 \%$ after the procedure and with a NASS score of 1 and 2 and EQ-5D less than 9 was classified as successful treatment, and a reduction in the VNS of less than $50 \%$ after the procedure with NASS score of 3 and 4 and EQ5D equal and more than 9 was classified as failed treatment. Patients who had subsequent surgery after the procedure were also deemed to have failed treatment.

\section{Statistical analysis}

Data were analyzed by SPSS version 16.0 software. The level of correlation between the pre-procedure and follow-up VNS, EQ-5D and NASS scores were determined using Pearson Correlation test, with $\mathrm{P}<0.05$ with $95 \%$ confidence intervals considered statistically significant. The effects of the variables (age, gender, symptom duration, level number pre-op EQ5D and pre-op VNS) to the results were analyzed using linear regression test, with $\mathrm{P}<0.05$ with $95 \%$ confidence intervals considered statistically significant. The paired samples t test was used to compare the means of the variables (VNS, EQ-5d and NASS) of the groups with $\mathrm{P}<0.05$ with $95 \%$ confidence intervals considered statistically significant.

\section{RESULTS}

All the patients completed the $1^{\text {st }}$ year follow-up visits. There was no significant difference between the groups respect to age $(p=0.275)$, gender $(p=0.497)$, level number $(p=0.705)$, symptom duration ( $p=0.814)$, VNS-pre $(p=0.06)$ and EQ-5D-pre $(p=0.09)$. All VNS, EQ-5D and NASS scores were significantly correlated with respect to their follow-up times $(P<0.01)$. The mean pre-procedure, post-procedure, $1^{\text {st }}$ month, $6^{\text {th }}$ months and $12^{\text {th }}$ month post-procedure VNSs, EQ-5Ds and NASSs were summarized in Figure 2. Significant differences were observed between the groups except for pre-op VNS. In early post-op VNS in FJ group in 1st month, $6^{\text {th }}$ months and $1^{\text {st }}$ year FJRF showed better results $(p<0.001)$. Pre-op VNS showed significant effect to pre-op NASS $(p<0.001)$.

There was no significant difference in the $1^{\text {st }}$ month $(p=1)$ and $6^{\text {th }}$ month $(p=0.13)$ follow-ups however there was significant difference respect to $12^{\text {th }}$ month $(p=0.04)$ NASS patients satisfactions scores. Increase in level number showed positive effect in NASS in FJRF group $(p=0.018)$ but no effect in FJI group ( $p=0.823$ ) in the $12^{\text {th }}$ month follow-up.

There was no significant difference with respect to $1^{\text {st }}$ month $(p=0.17), 6^{\text {th }}$ month $(p=0.22)$ and $12^{\text {th }}$ month $(p=0.11)$ post-procedure follow-ups in EQ-5D. Increase in level number showed positive effect in NASS in FJRF group $(p=0.05)$ but no effect in FJI group $(p=0.912)$ in the $12^{\text {th }}$ month follow-up. The success rate of the procedure with respect to follow-up periods was summarized in Figure 3. These were almost consistent and sustainable clinical improvement after both procedures over the 12 months period when VNS, EQ-5D and NASS progressively decreased. The success rate seems to be significantly better in FJRF. In the short term, FJI seems to be more effective than FJRF but in midterm follow-up FJRF had more satisfying results than FJRF.

These comparisons indicated that the therapeutic benefits of FJls occurred immediately by the injection, however the effect of FJRF begins a few weeks later. FJRF was performed to 10 patients who had FJl previously, after the $6^{\text {th }}$ month follow-up. None of the FJRF patients needed surgery after the procedure in the long-term follow-up period

There were no cases of infection, or new motor or sensory deficit after the both procedures in early or long-term followups. There have been rare complaints of small superficial burns after RF. In second group of our study, we observed burning-like sensation in the lesion-performed region and

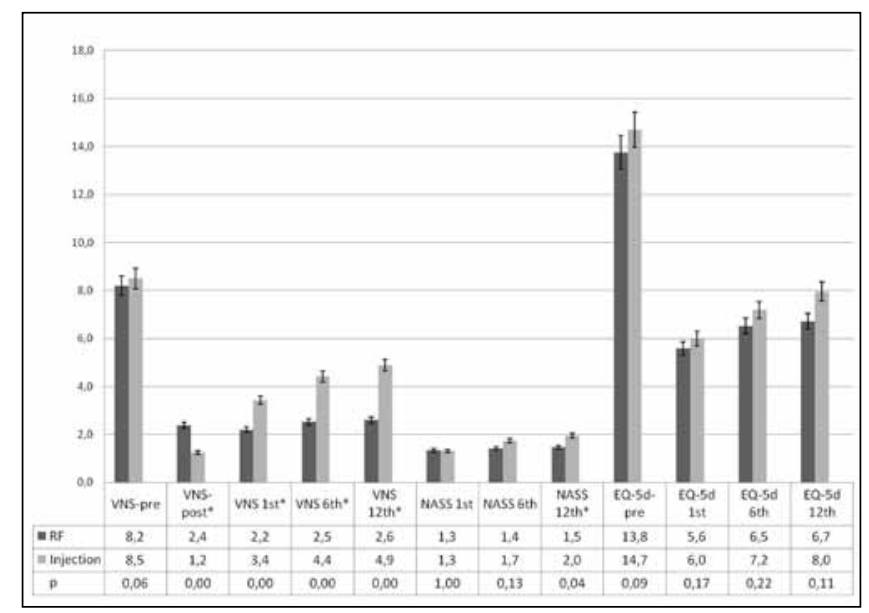

Figure 2: All VNS, EQ-5D and NASS scores respect to months.

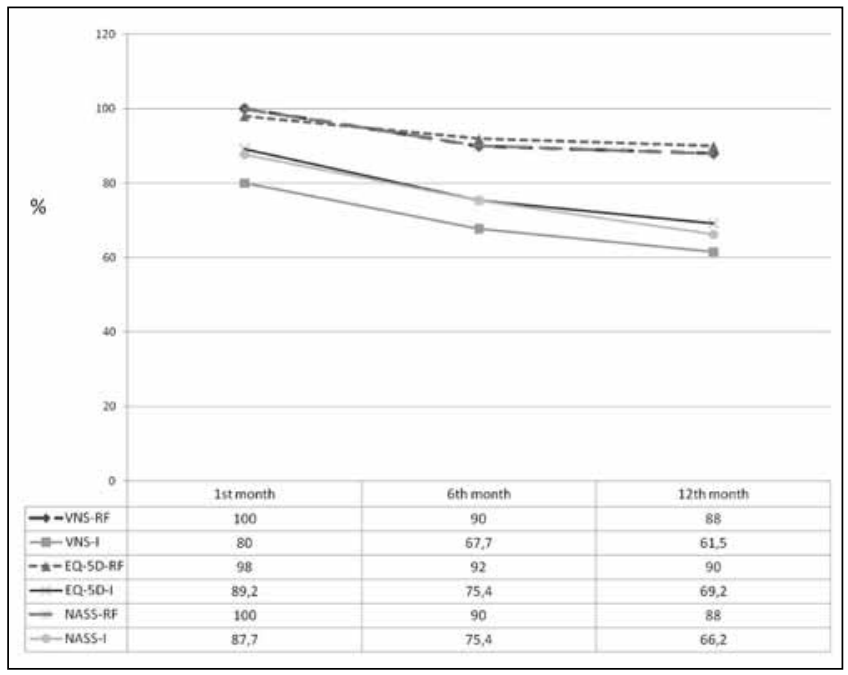

Figure 3: Success ratio of the patients respect to follow-up months. 
increase in severity of low back pain in two patients in the early follow-up period. After medication for neuropathy, all complaints resolved after 6-8 weeks and no additional procedure was required. In the long-term follow-up no exacerbation was experienced in the complaints neither in FJI nor in FJRF groups.

\section{DISCUSSION}

FJ arthrosis has been suggested as a cause of low back pain (10, 15). However, the exact cause is not clear. Some theories from mechanical alterations to vascular changes are present. Some patients may not feel any pain until degenerative changes in the FJs alter mechanical alignment $(10,15)$. Neuroanatomic and physiological studies have shown that lumbar FJs have abundant nerve supply and nociceptors (6). Radiofrequency neurotomy (RFN) of the medial branches of the dorsal rami and FJls are successful methods of treating FJ pain.

Bogduk (2) proposed to perform test blocks of a FJ, although controversial (33), to determine the target joint which may be the source of the patient's pain. This can be done by either an intraarticular injection of a local anesthetic or through medial branch blocks that innervate the target joint. However, a diagnosis cannot be made reliably on the basis of a single block, and false-positive rates as high as 38\% have been demonstrated (30). In our study we did not perform the test block of FJ. We did not use a diagnostic block to prevent its possible effect on the effectiveness of the procedure, and thus to decrease the rate of false positiveness in our series. In our study, 10 of 50 patients of RF group had previous successful FJl history and we observed better outcome with long-term pain relief in these patients. We enrolled only those patients having at least 2 of the 4 symptoms of facet syndrome, which are; local tenderness over one or more FJs, back pain aggravation by hyperextension and rotation, morning stiffness or pain increasing in the morning, and hip and buttock pain of a nonradicular distribution (36). The patient selection was made by experienced staff neurosurgeons by careful clinical examination and after seeing all patient's both static and dynamic graphics, lumbar computerized tomography, and lumbar magnetic resonance imaging to rule out other possible sources of low back pain.

Just after FJ the patient's pain typically resolves completely. While the immediate effect is related to the anesthetic, the main effect of the steroid may take 1-5 days to develop. The effect can last as long as 1-2 years or be as short as 1-2 months. Some patients never obtain relief even when the application of the procedure is correct. In our series $70 \%$ of the patients were satisfied at the 1 year follow-up. This rate was $90 \%$ in the FJRF group. Manchikanti et al. (21) showed equal effectiveness of local anesthetics with or without steroid over a period of one year in a randomized, doubleblind, controlled trial, indicating a lack of support for the proposition of inflammation in pain pathogenesis caused by FJs. The mechanism of action of local anesthetics providing such relief is not completely known.
Lynch and Taylor (19) reported that of 27 patients receiving intraarticular injections, total pain relief was observed in 9, whereas 2 patients in this treatment group experienced no relief. Carette et al. (5) reported a marked improvement in $42 \%$ of patients in the treatment group versus $33 \%$ of the control group at 1 month. However, at 6 months, only $22 \%$ in the treatment group and $10 \%$ in the placebo group demonstrated sustained improvement. This difference was not statistically significant. Carette et al. (5) concluded that intraarticular methyl-prednisolone was of little value in the treatment of patients with chronic low back pain. Lilius et al. (18) and Marks et al. (23) found no difference in effectiveness between their intervention groups. Marks et al. (23) observed that those with low back pain for more than 7 years were more likely to report good or excellent response than those with a shorter duration of pain. In our study symptom duration showed significant negative effect in $12^{\text {th }}$ month EQ-5D scores in FJRF group $(p=0.043)$ but not in FJI group $(p=0.175)$. In the procedure of medial branch block by injection, Manchikanti et al. (21) observed statistically significant pain relief and functional status improvement at 1 month, 6 months, and 12 months, compared to baseline measurements as in our study.

Slipman et al. (32), in a review of the evidence for the use of lumbar FJls and FJRF denervation in the treatment of chronic low back pain, found limited evidence for intraarticular injections in the lumbar spine and moderate evidence for RF in the lumbar spine.

In the Gallagher et al. (12) study, reduction in pain scores after lumbar FJRF was approximately $50 \%$ at 1 month and was sustained at 6 months. Van Kleef et al. (35) reported a higher rate of success in the treatment group compared with the control group at 3, 6, and 12 months. In the Leclaire et al. (17) study, at the end of 4 weeks, there was an improvement in the Roland-Morris (29) score by $8.4 \%$ and $2.2 \%$ in the RF and control groups, respectively. However, at 12 weeks there was no significant difference in the Roland-Morris (29) score, VAS, strength/mobility, and return-to-work status in both groups.

Dreyfuss et al. (9) reported that $87 \%$ of 15 patients obtained at least $60 \%$ pain relief 12 months status post FJRF, with $60 \%$ of the patients achieving at least $90 \%$ relief. In the study by Gofeld et al. (14), only the patients with an appropriate response to comparative double diagnostic blocks were evaluated and 55 of the 174 patients (31.6\%) experienced no benefit from the RF procedure, 119 patients $(68.4 \%)$ had well to excellent pain relief lasting from 6 to 24 months. They concluded that proper patient selection and anatomically correct FJRFs provides strong short-term and moderate longterm pain relief. Martinez-Suarez et al. (24) evaluated 252 patients with a diagnosis of lumbar FJ pain with RF neurotomy of medial branches. They reported effectiveness in $74.7 \%$ of cases. The effectiveness rate was $69.2 \%$ in FJ group and $88 \%$ FJRF in our study. This positive difference may be due to the physical therapy which was performed after 10 days of bed rest following the procedure (Table I).

In the RF procedure, improvement of $60 \%$ to $80 \%$ has been reported in studies excluding patients with previous back 
Table I: Success Rate of the Similar Series Cited in the Study

\begin{tabular}{|c|c|c|c|}
\hline EQ-5D & 1st month & 6th month & 1st year \\
\hline Civelek -FJRF & 98 & 92 & 90 \\
\hline Civelek -FJI & 89,2 & 75,4 & 69.2 \\
\hline Caretta-FJI (5) & 42 & 22 & - \\
\hline Gallaher-FJRF (12) & 50 & 50 & - \\
\hline Van-Kleef-FJRF (35) & 67 & 67 & 67 \\
\hline Dreyfuss-FJRF (9) & - & - & 87 \\
\hline Gofeld-FJRF $^{(14)}$ & - & - & 68.4 \\
\hline Martinez-Suarez-FJRF (24) & - & - & 74.7 \\
\hline
\end{tabular}

surgery $(27,28,31)$ whereas studies including patients with back surgery have reported approximately $40 \%$ improvement $(25,26)$. Manchikanti et al. (20) reported a $16 \%$ prevalence of lumbar FJ pain in a prospective study of 117 post surgical patients. In our study, $10 \%$ of the patients of FJ group and $12 \%$ in FJRF group had previous back surgery. This group had worse outcomes than the patients without previous back surgery (44\% satisfaction).

Kapural and Mekhail (16) documented post-RF muscular pain, superficial infections and postdenervation neuritis. North et al. (26) mentioned paradoxical exacerbation of pain secondary to deafferentation. In the FJRF group of our study, we observed burning-like sensation in the lesion-performed region and increase in severity of low back pain in two patients. Each medial branch also contains efferent fibers communicating motor activity to the adjacent multifidus muscle. Radiofrequency lesioning of the medial branch interrupts both the afferent and efferent neurons. This may be the probable reason. In our opinion, this may be due to insufficient or partial denervation leading to neuropathic pain. After medication for neuropathy, all complaints resolved after 6-8 weeks. In one study, the administration of corticosteroid was found to reduce the incidence of post-procedure pain after radiofrequency denervation (8).

The major limitation of our study is that this study did not include a control group. Placebo control in any neural blockage is an extremely difficult and very important ethical problem.

Both procedures are effective, easy, and safe treatment modalities for the treatment of facet syndrome. In conclusion, in selected patients, FJRF appears to be more effective. Additionally, FJI is more cost effective than RF (Approximate costs were FJI: $100 \$$ and FJRF: $700 \$$ ). To our knowledge, in patients with chronic lumbar pain, the first choice should be the FJl and if pain reoccurs after a period of time or FJl is not effective, RF procedure should be used for the treatment of chronic lumbar pain.

\section{REFERENCES}

1. Bogduk N: A narrative review of intraarticular corticosteroid injections for low back pain. Pain Med 6:287-296, 2005

2. Bogduk N: International Spinal Injection Society guidelines for the performance of spinal injection procedures. Part 1: Zygapophyseal joint blocks. Clin J Pain 13:285-302, 1997

3. Boswell MV, Colson JD, Sehgal N, Dunbar EE, Epter R: A systematic review of therapeutic facet joint interventions in chronic spinal pain. Pain Physician 10:229-253, 2007

4. Boswell MV, Colson JD, Spillane WF: Therapeutic facet joint interventions in chronic spinal pain: A systematic review of effectiveness and complications. Pain Physician 8:101-114, 2005

5. Carette S, Marcoux S, Truchon R, Grondin C, Gagnon J, Allard Y, Latulippe M: A controlled trial of corticosteroid injections into the facet joints for chronic low back pain. $\mathrm{N}$ Engl J Med 325:1002-1007, 1991

6. Cavanaugh JM, Lu Y, Chen C, Kallakuri S: Pain generation in lumbar and cervical facet joints. J Bone Joint Surg Am 88: 63-67, 2006

7. Croft PR, Macfarlane GJ, Papageorgiou AC, Thomas E, Silman AJ: Outcome of low back pain in general practice: $A$ prospective study. BMJ 316: 1356-1359, 1998

8. Dobrogowski J, Wrzosek A, Wordliczek J: Radiofrequency denervation with or without addition of pentoxifylline or methylprednisolone for chronic lumbar zygapophysial joint pain. Pharmacol Rep 57:475-480, 2005

9. Dreyfuss P, Halbrook B, Pauza K, Joshi A, McLarty J, Bogduk N: Efficacy and validity of radiofrequency neurotomy for chronic lumbar zygapophysial joint pain. Spine 25:1270-1277, 2000

10. Eubanks JD, Lee MJ, Cassinelli E, Ahn NU: Prevalence of lumbar facet arthrosis and its relationship to age, sex, and race: An anatomic study of cadaveric specimens. Spine 32:2058- 2062, 2007

11. Frymoyer JW, Pope MH, Clements JH, Wilder DG, MacPherson B, Ashikaga T: Riskfactors in low back-pain:An epidemiological survey. J Bone Joint Surg Am 65(2):213-218, 1983

12. Gallagher J, Petriccione Di Vadi P L, Wedley J R, Hamann W, Ryan P, Chikanza I, Kirkham B, Price R, Watson M S, Grahame $R$, Wood S: Radiofrequency facet joint denervation in the treatment of low back pain: A prospective controlled doubleblind study to assess its efficacy. Pain Clin 7(3):193-198, 1994 
13. Geurts JW, van Wijk RM, Stolker RJ, Groen GJ: Efficacy of radiofrequency procedures for the treatment of spinal pain: A systematic review of randomized clinical trials. Reg Anesth Pain Med 26:394-400, 2001

14. Gofeld M, Jitendra J, Faclier G: Radiofrequency facet denervation of the lumbar zygapophysial joints: 10-year prospective clinical audit. Pain Physician 10:291-300, 2007

15. Kalichman L, Li L, Kim DH, Guermazi A, Berkin V, O'Donnell CJ, Hoffmann U, Cole R, Hunter DJ: Facet joint osteoarthritis and low back pain in the community-based population. Spine 33:2560-2565, 2008

16. Kapural L, Mekhail N: Radiofrequency ablation for chronic pain control. Curr Pain Headache Rep 5:517-525, 2001

17. Leclaire R, Fortin L, Lambert R, Bergeron YM, Rossignoi M: Radiofrequency facet joint denervation in the treatment of low back pain: A placebo-controlled clinical trial to assess efficacy. Spine 26(13):1411-1417, 2001

18. Lilius G, Laasonen EM, Myllynen P, Harilainen A, Gronlund G: Lumbar facet joint syndrome: A randomized clinical trial. J Bone Joint Surg 71B:681-684, 1989

19. Lynch MC, Taylor JF: Facet joint injection for low back pain: $A$ clinical study. J Bone Joint Surg 68:138-141, 1986

20. Manchikanti L, Manchukonda R, Pampati V, Damron KS, McManus CD: Prevalence of facet joint pain in chronic low back pain in post surgical patients by controlled comparative local anesthetic blocks. Arch Phys Med Rehabil 88(4):449-455, 2007

21. Manchikanti L, Singh V, Falco FJE, Cash KA, Pampati V: Lumbar facet joint nerve blocks in managing chronic facet joint pain: One-year follow-up of a randomized, double-blind controlled trial: Clinical trial NCT00355914. Pain Physician 11:121-132, 2008

22. Manchikanti L, Singh V, Pampati V, Damron KS, Barnhill RC, Beyer C, Cash KA: Evaluation of the relative contributions of various structures in chronic low back pain. Pain Physician 4:308-316, 2001

23. Marks RC, Houston T, Thulbourne T: Facet joint injection and facet nerve block: A randomized comparison in 86 patients with chronic low back pain. Pain 49:325-328, 1992
24. Martinez-Suarez JE, Camblor L, Salva S, De Jongh WA: Thermocoagulation of lumbar facet joints. Experience in 252 patients. Revista de la Sociedad Espanola del Dolor 12: 425-428, 2005

25. McCulloch JA, Organ LW: Percutaneous radiofrequency lumbar rhizolysis. Can Med Assoc J 116:30-32, 1977

26. North RB, Han M, Zahurak M, Kidd DH: Radiofrequency lumbar facet denervation: Analysis of prognostic factors. Pain 57: 77-83, 1994

27. Ogsbury JS 3rd, Simon RH, Lehman RA: Facet denervation in the treatment of low back syndrome. Pain 3:257-263, 1977

28. Oudenhoven RC: Articular rhizotomy. Surg Neurol 2:275-278, 1974

29. Roland M, Morris R: A study of the natural history of low back pain. Part 1: Development of a reliable and sensitive measure of disability in low-back pain. Spine 8:141-144, 1983

30. Schwarzer AC, Aprill CN, Derby R, Fortin J, Kine G, Bogduk N: The false-positive rate of uncontrolled diagnostic blocks of the lumbar zygapophysial joints. Pain 58:195-200, 1994

31. Shealy CN: Facet denervation in the management of back and sciatic pain. Clin Orthop 115:157-164, 1976

32. Slipman CW, Bhat AL, Gilchrist RV, Issac Z, Chou L, Lenrow DA: A critical review of the evidence for the use of zygapophyseal injections and radiofrequency denervation in the treatment of low back pain. Spine 3:310-316, 2003

33. Slozar PJ Jr, White AH, Wetzel FT: Controversy: The use of selective nerve root blocks: Diagnostic, therapeutic, or placebo? Spine 23:2253-226, 1998

34. van den Hoogen HJ, Koes BW, Devillé W, van Eijk JT, Bouter LM: The prognosis of low back pain in general practice. Spine 22:1515-1521, 1997

35. van Kleef M, Barendse GA, Kessels A, Voets HM, Weber WE, de Lange $S$ : Randomized trial of radiofrequency lumbar facet denervation for chronic low back pain. Spine 24(18): 1937-1942, 1999

36. Yilmaz C, Kabatas S, Cansever T, Gulsen S, Coven I, Caner $\mathrm{H}$, Altinors $\mathrm{N}$ : Radiofrequency facet joint neurotomy in treatment of facet syndrome. J Spinal Disord Tech 23(7):480485,2010 